\title{
Editorial: Special Issue Neurovision
}

\author{
Ulf T. Eysel • K. P. Hoffmann
}

Published online: 12 November 2009

(C) Springer-Verlag 2009

Visual system research has a longstanding tradition at the Ruhr University in Bochum and it benefitted from continuous support by the German Research Foundation (Deutsche Forschungsgemeinschaft, DFG) granted first for a Research Unit and then the Collaborative Research Center (CRC) "Neurovision" between 1990 and 2007. This special issue of EBR named "Neurovision" concludes this period and summarizes our achievements.

The joint venture in vision research in Bochum started in 1990 with the DFG Research Unit "Neurobiology of the visual system-Neurovision" and continued from 1996 onwards in the Collaborative Research Center "Neuronal mechanisms of vision-Neurovision". The Center was devoted to research in visual neuroscience from early developmental mechanisms to cellular and systems properties and further up to higher and visuomotor brain functions, with a wide range of methodical approaches including, molecular biology, cellular physiology, systems neurophysiology, neuroanatomy, and computational neuroscience. After 12 years of continuous and generous funding by the DFG, this CRC had to come to an end.

In this issue of EBR, we want to present some of the highlights from the research, which was funded over the last triannual period in the CRC Neurovision. Naturally, most of the results from the previous periods have already been published and papers are given in the reference lists. The development of specific research themes and the

U. T. Eysel ( $\square)$

Faculty of Medicine, Ruhr-University, Bochum, Germany

e-mail: eysel@rub.de

\section{K. P. Hoffmann}

Faculty of Biology and Biotechnology,

Ruhr-University, Bochum, Germany

e-mail:kph@neurobiologie.rub.de projects of the CRC over the last 12 years are represented in the reviews in this volume, and the newest results accumulated during the last funding period are described in the original research articles. With this special issue, we want to especially acknowledge the support we received from the German Research Foundation.

One goal of our CRC was to investigate basic mechanisms of vision, developmental processes that lead to structure and function of the visual system, synaptic mechanisms involved in the generation of visual properties in early visual networks of the brain, and mapping of these properties in primary visual areas. Important progress was made in understanding the relationships of structure and function with studies combining optical imaging of cortical specificity maps and sophisticated 3D reconstructions of the underlying visual cortical connections. Other strongholds were excitatory and inhibitory synaptic processing and molecular biology of developmental processes in the visual system as exemplified in this volume of EBR.

Another major goal of our CRC was to elucidate on how vision is integrated with visuomotor or orienting mechanisms and memory functions and how visual cognitive properties emerge in the left or right cerebral hemisphere to enable goal-directed behavior. In one set of studies, simultaneous multielectrode recording in visual (area MT) and motor (motor cortex) areas in awake monkeys performing a tracking task with a manipulandum clarified the role of feedback from actions on movement perception. In a comparative neurobiological approach, common principles of flow-field analysis and mechanisms by which the distance travelled can be deduced from flow fields in monkeys and seals were compared. Vision during saccades and head bobbing was studied in monkeys and pigeons; also, for pigeons the question of lateralization of cognitive visual functions was solved. A dual coding of visual 
asymmetries was found in the pigeon brain: the interaction of bottom-up and top-down systems.

An interesting modification of visuomotor behavior can be found in albinos. Albino ferrets and rats show no optokinetic reaction. The deficit was localized in neurons of the accessory optic system. These neurons are highly direction selective in normal, but pathologically unspecific in albino animals. The retinal projections to these neurons look more or less normal, but the direction selectivity may be lost due to their altered inhibitory mechanisms.

A third major area of research in this CRC was the plasticity of the visual system, both in normal subjects and following lesions in the adult brain. These studies of plasticity spanned experimental work from molecular biology over in vitro investigation of synaptic transmission to studies in behaving animals and systems research into the adaptation and recovery of the visual brain in response to lesions of the retina and the visual cortex. For example, both electrical and transcranial magnetic stimulation, as well as retinal and cortical lesions induce changes in functional maps and transmitter systems of the visual cortex that shine light on the functional adaptability of the visual system and some of the underlying mechanisms.

Many more results have been published from Neurovision between 1996 and 2009 by a total of 30 researchers that were PIs and members of the CRC (in alphabetical order with current academic status and location): Bremmer, F. (Prof., Marburg), Dehnhardt, G. (Prof., Rostock), Dermietzel, R. (Prof., Bochum), Diekamp, B. (PD, Bochum), Dinse, H. (PD, Bochum), Distler, C. (PD, Bochum), Eysel, U.T. (Prof., Bochum), Faissner, A. (Prof., Bochum), Funke, K. (Prof., Bochum), Gottmann, K. (Prof., Düsseldorf), Güntürkün, O. (Prof., Bochum), Hatt, H. (Prof., Bochum), Heumann, R. (Prof., Bochum), Hoffmann, K.P. (Prof., Bochum), Kisvárday, Z.F. (Prof., Debrecen, Hungary),
Kruse, W. (Dr., Bochum), Lappe, M. (Prof., Münster), Leßmann, V. (Prof., Magdeburg), Manahan-Vaughan, D. (Prof., Bochum), Mittmann, T. (PD, Bochum), Schmidt, M. (PD, Bochum), Schöner, G. (Prof., Bochum), Spengler, F. (Dr., Bochum), Troje, N. (Prof., Kingston, Ontario, Canada), Volgushev, M. (Prof., Storrs, Connecticut, USA), von der Malsburg, C. (Prof., Frankfurt), von Seelen, W. (Prof., Bochum), Wahle, P. (Prof., Bochum), Wörgötter, F. (Prof., Göttingen), Zoidl, G. (PD, Bochum).

In summary, over the 12 years of funding substantial progress in understanding the development, the basic functions and behavioral implications as well as the plastic changes in the adult brain due to training or lesions has been accumulated in our consortium. We would be most rewarded, if the readers of this volume would find her or his chapters of interest stimulating and meaningful.

U. T. Eysel, K. P. Hoffmann

\section{Acknowledgments}

The following papers that have been written and were originally accepted for this special issue have been or will be published elsewhere: Besser M, Horvat-Bröcker A, Eysel UT, Faissner A (2009) Differential expression of receptor protein tyrosine phosphatases accompanies the reorganisation of the retina upon laser lesion. Exp Brain Res 198(1):37-47. DOI: 10.1007/s00221-009-1932-0 (This paper was erroneously published in a regular volume.) Bremmer F, Kubischik M, Pekel M, Hoffmann, KP, Lappe M (2009) Visual selectivity for heading in monkey area MST. EBR 200, in press. (This paper has been elected by the editors of EBR to be part of the EBR 200th anniversary volume). 